\title{
A Study on the Operation Strategy of Food WeChat Public Accounts - Taking "Rishi-Ji" as an Example
}

\author{
Chen Chen \\ School of Management \\ Wuhan University of Science and Technology \\ Wuhan China \\ 969771839@qq.com \\ Liu Chaojie \\ School of Management \\ Wuhan University of Science and Technology \\ Wuhan China
}

\author{
Tong Zeping* \\ School of Management \\ Wuhan University of Science and Technology \\ Wuhan China \\ Liao Menghan \\ School of Management \\ Wuhan University of Science and Technology \\ Wuhan China
}

\begin{abstract}
This paper adopts a case study approach to analyze the operational strategy of the "Rishi-Ji" WeChat public account and summarizes its successful experience. Through the analysis of individual cases, the operation strategy of the "Rishi-Ji" WeChat public account was summarized to provide a reference for the food WeChat public accounts.
\end{abstract}

Keywords-Food; Operating strategy; "Rishi-Ji"; WeChat public account

\section{INTRODUCTION}

\section{A. Research background and significance}

With the improvement of people's living standards, people are paying more and more attention to the food culture, and people's demand for food-related information is also increasing. In recent years, there have been a large number of food-related food documentaries, food-related variety shows, and gourmet food applications. Food We-Media has also grown vigorously and has become a topic worthy of attention and research. With the advent of the mobile Internet era, people's access to food information is also more through food We-Media such as Weibo and WeChat public accounts.

According to statistics, as of the end of 2017, there are more than 80,000 food WeChat public accounts. "Rishi-Ji" stood out among many WeChat public accounts and has become a success story in this field.

Studying the "Rishi-Ji" WeChat public account has certain academic and practical significance. It not only makes up for the academic research on the food WeChat public accounts, but also serves as a reference for the operation of other food WeChat public accounts.

\section{B. Research object}

Ri: Time. Shi: food. Ji: records, diary. This is the origin of the name "Rishi-Ji". At the end of 2013, Jiang Xuan, the founder of "Rishi-Ji", led his team to create a food micro-video < Gingerbread man for Christmas>. The first phase of the video came out strongly on Youku and Sina Weibo [1]. In 2014 Jiang Xuan and his studio started to formally operate the "Rishi-Ji" We-Media brand. And at the beginning of the year, the "Rishi-Ji" WeChat public account was opened. It is used to push the gourmet micro video and gourmet soft food shot. The theme-"heal your heart and stomach warmly"- has attracted many fans,

According to the latest data published in the "Rishi-Ji": "Rishi-Ji" WeChat Public Account has 12,500 fans. The average headline reads $100,000+$, and the non-headline average reads $57,000+$. We can conclude that the operation of "Rishi-Ji" WeChat public account has been quite successful from the data.

\section{Main content and innovation}

\section{1) Main content}

The main content of this article is divided into six chapters.

The first chapter is introduction. The second chapter is the literature review, mainly combing the research status at domestic and foreign. The third chapter is about the current status of the operation of the food WeChat public accounts. The fourth chapter analyzes the operational strategy of "RishiJi" WeChat public account and analyzes the case as the key content of this study. The fifth chapter is the inspiration for the operation of food WeChat public accounts. Chapter 6 is the conclusion. 


\section{2) Innovation}

After a search on the CNKI, there have been few studies on the WeChat public accounts in the existing literature. At present, there is no research on the food WeChat public accounts. The study of this paper makes up for the gap in this field. This article takes the successful case of the food WeChat Public Account-"Rishi-Ji"as the research object, has a distinctive personality and operating system, and has a relatively novel research on its operating strategy.

\section{LITERATURE REVIEW}

Searching on the subject of "WeChat public accounts" on CNKI has a total of 10205 articles. There are 5865 periodical articles and 395 dissertations. According to the chronological order of publishing, it was found that the first Article related to "WeChat public accounts" was published in September 2013, Wu Ke's Using WeChat public accounts to establish a platform for interactive exploration and practice of general education courses [2]. Until 2016, there was a lot of research on "WeChat public accounts".

The research on WeChat public accounts has a communication effect. For example, Fan Jing's The WeChat public accounts research results research and sample analysis shows that the corporate WeChat public accounts spread well and far exceeds the tradition media [3].

About the public accounts marketing book, The WeChat Secret: New Marketing in the Smart Phone Era, co-edited by more than a dozen industry professionals such as $\mathrm{Su}$ Gao, had proposed that WeChat marketing is an F2F (face to face) marketing[4]. Shen Zhouyu's WeChat Marketing: The Mobile Internet Age, Such Marketing Is Right analyzes the reasons why the company's WeChat operations are on fire from a higher level and looks at how WeChat should develop in the next decade [5].

There are only 26 related articles on the topic of "food WeChat public accounts" on CNKI. Through the study of the above literature and works, this paper has a deep understanding of the operation, dissemination and marketing advantages of WeChat public accounts. And combine these topics with knowledge to lay the groundwork for the next study and fill the gaps in research related to the food WeChat public accounts.

\section{FoOd WeChat PUblic ACCOUNTS OPERATION STATUS}

There are two obvious problems with the operation of the food WeChat public accounts: Firstly, the quality of most food WeChat public accounts is uneven. Simply relying on the visual stimuli of food itself to attract users without finding a connection point with the user, not to dig out the other value behind food. What's more, its publication content also includes health care, social news, chicken soup for the soul and so on. It is very unprofessional and it is not conducive to the retention of users and the formation of user stickiness. Secondly, the phenomenon of homogeneity is serious, and both the output content and the operating model are almost the same. They have not formed their own unique operating model and have not found a clear profit model [6].
There may be two reasons for the above problems: First, the threshold for WeChat public accounts creation is low, everyone can apply, many people create food class WeChat public accounts is just a blind pursuit; second, some food WeChat public accounts lack planned operations, it is difficult to maintain the long-term update of high-quality original works based solely on personal strength.

\section{ANALYSis Of OPERATION STRATEgy OF "RISHI-JI" WECHAT PUBLIC ACCOUNT}

\section{A. Analysis Of Content Composition Of Rishi-Ji WeChat Public Account}

The interface of "Rishi-ji" WeChat public account consists of three sections, namely cooking, chatting, and selling, whose contents include food recipes, meal listening, cat raising, good selling and soft-text advertising.

\section{1) Food Recipes}

As a sub-sector of cooking, Food Recipes include home style dishes, beverage practices and food tweets, clear at a glance.

First, the interesting article titles, pointing out the themes, don't have to attract their users by gimmicks. For example, the titles "How delicious can the fried rice be so that $i$ once refuse to relinquish it even under the danger of being slapped", "Don' t throw away the unfinished toast, it would turn to exquisite dessert".

Second, with detailed text explanations, pictures or gourmet-making videos form the body of articles. As the subject to attract consumers, short food videos gradually develop numerous branches to retain consumers, when demonstrating the delicacy of food in a literary and warm color.

Finally, what is worth mentioning is that in the aspect of food, Rishi-ji will choose common food which can be bought in a downstairs store, such as spicy hot pot and egg-fried rice [7]. It will also try it' $s$ best to maintain exquisiteness and inexpensiveness in the election of backgrounds and kitchenware.

\section{2) Meal Listening}

In Rishi-ji WeChat public account, Meal Listening belongs to the section of "Feed Your Ears With a Story". As the audio pushed by the public account, Meal Listening tells the cozy processes of cooking or eating. Every night at ten o'clock, users can punctually hear the impact sound of pots and pans, the boiling sound of hotpot, the sound of consuming food, and the meowing sound of a cat every now and then.

The food audio pushed punctually Late at night has got so strong response that every audio has been read more than 100,000 times with many comments or thumbs. 


\section{3) Cat Raising}

Both in Rishi-ji's short food videos and Meal Listening series, there exist a cat called Su Bing, the host of the Cat Raising section, who has also played a considerable role in the operation of the WeChat public account.

This section has totally promoted 12 articles themed "Su Bing's Daily Routine" till now. Rishi-ji's team will take daily snapshots of Su Bing. Match these snapshots with interesting copywriting in Su Bing's tone, Su Bing's facial expression and actions with humorous dialogues, which makes the tweets more interesting. Under the efforts of Rishi-ji's team, Su Bing has turned into a cat with rich personal characteristics, cute, soft, cool, sentimental, angry or tricky from time to time [8].

\section{4) Good Selling}

Rishi-ji opens a WeChat store as a mini app on the interface of the WeChat public account. The store sells self -produced coffee, food, cups and other gadgets. Take Su Bing as the package image prototype of coffee and food, cups have the fresh and artistic design, with reasonable prices, successfully attracting many loyal fans of Rishi-ji and visual lovers.

\section{5) Soft-text Advertising}

The soft-text advertisements of Rishi-ji are mainly implanted into short food videos without affecting the quality of content, like food utensils and materials used in making food, Lan Zhou cigarettes besides the filmed ashtray on the table. The advertisements have successfully combined goods and video into one without any abruptness. Till now, Rishi-ji has cooperated with many brands including Starbucks, Meiji, Zojirushi, Panasonic and Midea.

What's more, hard-text advertisements are also applied. Rishi-ji chooses to promote one good started with a story, with experienced feelings, and ended with product links, thereby introducing the good to its users.

\section{B. Analysis of Operation Strategy of Rishi-Ji WeChat Public Account}

1) Closely concentrating on the users

Rishi-ji is maximizing its form of One Person, One Cat, And One Story according to its own characteristics. It's tweets and content production have tightly focused on users who love food, enjoy visual aesthetics, and love cats.

The accurate positioning of users has three advantages:

First, convert passivity into initiative through accurate screening of target users. Once the user nature is defined, promotion content, time, frequency and other operation activities can be carried out around this positioning. After this positioning, promotion content is related with cooking, food and cats, as well as goods of the e-commerce platform also surround the theme, which not only saves the users' energy, but also makes Rishi-ji more distinctive and professional.

Second, the WeChat operation strategies of Rishi-ji is much more scientific according to the accurate positioning of users. The users of Rishi-ji WeChat public account are those who love food, prefer to make delicious food by themselves, and are more willing to share their achievements, to learn from and exchange experience with each other. Therefore, Rishi-ji chooses to concentrate on interacting with its users, so as to improve the loyalty of its fans.

Third, the users' benefits can be maximized. First of all, the accurate positioning has saved labor and financial cost for Rishi-ji's team. It is unnecessary for the team to spend much more time managing the user survey or carrying out different operation activities for different groups. In the next place, the highly targeted WeChat operation can offer its users better service, enhance their experience, develop tighter relationship with them, and then bring more economic benefits.

\section{2) Insisting On Quality And Independent Originals}

Rishi-ji keeps focusing on delicious food, and spreading the food mainly in the method of short food videos. Every Rishiji's video has adopted the content mode of cooking, lovely pets, and stories. The unification of the mode helps to centralize the watching feelings and produce originals. Throughout the articles promoted by Rishi-ji, recipe articles and other content are created by Rishi-ji itself, almost without any forwarded or referenced articles [9].

\section{3) Creating a Fresh Style}

"Fresh" is a subculture phenomenon of youth generated among teenagers in Chinese developed cities with the development of the internet in early 21 st century [10]. Both videos and tweets of Rishi-ji have a distinct fresh Japanese style. The young 90s fans have been deeply attracted by the aesthetic comfortable state and the cozy home scenes created by Rishi-ji.

\section{4) Exploring Diversified Profit Models}

The market positioning of WeChat public platform decides its profit models [11]. After segmenting the user market in detail, Rishi-ji has realized differentiated market positioning. According to the needs and features of target users, it's market operation achieves great business performance.

According to the promotion content of Rishi-ji, its profit models mainly include the following types.

One is the advertisement charges, which has been adopted by all the WeChat public accounts owning a large number of fans. Based on the data from Rishi-ji's official website, its single advertisement charge ranges from 400,000 yuan to 500,000 yuan and a whole set charges at least two million yuan.

The other one is selling related goods of Rishi-ji. For example, there once appeared a wooden speaker in a Rishi-ji video, which was a Rishi-ji customized one jointly launched by a Speaker brand and Rishi-ji. The Speaker was for sale in the Rishi-ji WeChat store after the program. Although it was sold at a high price of 1499 yuan, more than 20 were consumed within just two days. 


\section{THE ENLIGHTENMENT OF "RISHI-JI" ON THE OPERATION STRATEGY OF FOOD PUBLIC ACCOUNTS}

"Rishi-Ji" is the WeChat public account targeted by food, for the majority of love food groups, its content is also completely consistent with the target group. Many catering industry use WeChat media to explore new media integration and development model, trying to expand their visibility, so as to profit. As a more successful case of the food public accounts, "Rishi-Ji" is of great significance to the construction and operation of food WeChat public account by referring to the operation mode of WeChat public platform of "Rishi-Ji".

\section{A. Exploring the meaning behind food}

The food public accounts can't just stay on the food surface, it must constantly explore the meaning behind food. Everyone has different experiences and memories of food, and the understanding and definition of food are also necessarily different.

Different regions have different food tastes, there is enough space to explore the content of the food that is subdivided into different regions. Different diets also represent different lifestyles. Some people are keen to discover and try various styles of restaurants, while others enjoy the process of cooking food by themselves; some people love to eat meat, while others insist on vegetarian diet. Therefore, the useful functional attributes of food are the most basic values, it is a must-have content for food-related media, and people-related emotions, cultures, etc., belong to higher levels of value. There is more space in the content of food from the media. Being good at digging deeper values and meanings of food can better find emotional connection points with consumers.

\section{B. Create food branding}

Currently the overall degree of branding of food public accounts is low. The content of some public accounts is to forward and process other food self-media content. So food public accounts are often heavily homogenized in content. It is because there is no rise to the brand, so there is no difference from other similar products. The transformation of extensive content production into the brand's construction and shaping is the long-term path from the food media.

How to model the food public accounts, First of all, to create their own Logo, to establish their own cultural slogans. Secondly, we must accurately position ourselves around our core content

\section{Pay attention to the construction of cross-domain model}

Today, WeChat public accounts have passed the fan bonus period, the number of food public accounts is still increasing. Want to attract many fans with high quality content and word of mouth, these features of the WeChat public accounts alone cannot survive the fierce competition. Even if you attract enough fans, it is difficult to maintain them, let alone make money from it. If a company wants to achieve long-term development, it must establish a long-term production chain, build a long cultural industry chain, fully integrate platform resources, develop its own brand in multiple fields, and influence each other to achieve the purpose of operation.

Of course, the status of different food public accounts is different. This requires the public accounts to confirm the development stage in which they are located, and whether they are mature enough to consider the realization of liquidation It also requires that the decision-makers and teams carefully balance the relationship between user experience and profit realization, proceed from the long-term interests as far as possible, and conduct commercialization without affecting existing user experience and feelings. Ultimately in the business model, we must choose according to its own development status, content types, operating models, market status and a series of comprehensive factors [12].

\section{CONCLUSION}

The development of new media has brought new opportunities for food online development. WeChat public accounts have become the trend of the food industry. However, most food WeChat public accounts did not achieve the desired goal. "Rishi-Ji" public accounts is consistent with the positioning of food public accounts. Analysis of the "Rishi-Ji" WeChat public accounts operation strategy, summarize important tips for the operation of food WeChat public accounts. First of all, it is necessary to explore the meaning behind food; Second, to create a brand of food content; Third, to focus on the construction of a cross-domain model;

The successful operation of "Rishi-Ji" provides a mature model for the operation of the food WeChat public accounts. It also requires more researchers and companies to strengthen the research and practice of food $\mathrm{WeChat}$ public accounts in order to explore more mature operational strategies. Provide new directions.

"Rishi-Ji" is still under development. Its content production and operation activities are constantly changing. New things will continue to emerge. This article is only part of the periodic summary of the development of public accounts operation. I will also continue to pay attention to research on the operation strategies of the public accounts, pay attention to the latest trends in this field, and make my own contribution to research in the field of public accounts. 


\section{REFERENCES}

[1] Wang Qiyu. Delicate Emotional Expression in the Life Ceremony-On the Artistic Emotional Expression of the Series of Emotional Food Short Film "Rishi-Ji" [J]. News Research Guide, 2016,7(03):124. (In Chinese)

[2] Wu Ke. Using WeChat public accounts to establish a platform for interactive exploration and practice of general education courses [J]. Modern Medicine and Health, 2013, 29(17):2690-2691. (In Chinese)

[3] Fan Jing. The WeChat public accounts research results [J]. Modern Commerce,2016. 24:14-15. (In Chinese)

[4] Su Gao. WeChat Secret: New Marketing in the Smart Phone Era [M]. Tsinghua University Press, 2014:56-57. (In Chinese)

[5] Shen Zhouyu. WeChat Marketing: The Mobile Internet Age, Such Marketing Is Right [M]. China Federation of Industry and Commerce Press, 2014:29(In Chinese)

[6] Mi Jiefen. (2016). A Study on Operation Strategy of Food We-Media-Taking "Rishi-Ji" as an Example. Master Thesis. Guang Zhou: Jinan University. (In Chinese)

[7] Yang Xunran. (2016), 4 million fans of "Rishi-Ji", starting from the food short video, do not do electricity providers, so implantation. Business State, 4:28-29(In Chinese)

[8] She Ying. Rishi-Ji: Food and cats are only warm [N]. Economic Daily, 2018-01-17(008). (In Chinese)

[9] Liu Min. (2017). "Xia Chu Fang" Research on Content Production and Content Marketing Strategy of WeChat Public Number. Master Thesis. Anhui Province: Anhui University. (In Chinese)

[10] Cai Qi. (2013), Small Fresh Subculture in Network Virtual Community. Hunan University Journal of Social Sciences, 42(6). (In Chinese)

[11] Di Yazheng. (2014). Research on Profit Strategy of Self-Media Platform. Master Thesis. Beijing: eijing University of Posts and Telecommunications. (In Chinese)

[12] Su Gao. (2015). Win on the mobile: mobile e-commerce marketing Raiders. People Post Press, 22-27. (In Chinese) 